\title{
Revisiting keratoconus diagnosis and progression classification based on evaluation of corneal asymmetry indices, derived from Scheimpflug imaging in keratoconic and suspect cases
}

\author{
This article was published in the following Dove Press journal: \\ Clinical Ophthalmology \\ 25 July 2013 \\ Number of times this article has been viewed
}

\section{Anastasios John \\ Kanellopoulos ${ }^{1,2}$ \\ George Asimellis' \\ 'Laservision.gr Eye Institute, Athens, Greece; ${ }^{2}$ New York University School of Medicine, New York, NY, USA}

Video abstract

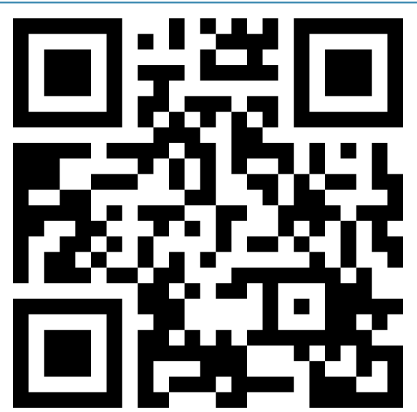

Point your SmartPhone at the code above. If you have a QR code reader the video abstract will appear. Or use: http://dvpr.es/IIvcPix

Correspondence: Anastasios John Kanellopoulos Laservision.gr Institute,

17 Tsocha str, Athens II52I, Greece

Tel +30 2107472777

Fax +30210747 2789

Email ajk@brilliantvision.com
Purpose: To survey the standard keratoconus grading scale (Pentacam ${ }^{\circledR}$-derived AmslerKrumeich stages) compared to corneal irregularity indices and best spectacle-corrected distance visual acuity (CDVA).

Patients and methods: Two-hundred and twelve keratoconus cases were evaluated for keratoconus grading, anterior surface irregularity indices (measured by Pentacam imaging), and subjective refraction (measured by CDVA). The correlations between CDVA, keratometry, and the Scheimpflug keratoconus grading and the seven anterior surface Pentacam-derived topometric indices - index of surface variance, index of vertical asymmetry, keratoconus index, central keratoconus index, index of height asymmetry, index of height decentration, and index of minimum radius of curvature - were analyzed using paired two-tailed $t$-tests, coefficient of determination $\left(\mathrm{r}^{2}\right)$, and trendline linearity.

Results: The average \pm standard deviation CDVA (expressed decimally) was $0.626 \pm 0.244$ for all eyes (range 0.10-1.00). The average flat meridian keratometry was (K1) $46.7 \pm 5.89 \mathrm{D}$; the average steep keratometry (K2) was $51.05 \pm 6.59 \mathrm{D}$. The index of surface variance and the index of height decentration had the strongest correlation with topographic keratoconus grading $(P<0.001)$. CDVA and keratometry correlated poorly with keratoconus severity.

Conclusion: It is reported here for the first time that the index of surface variance and the index of height decentration may be the most sensitive and specific criteria in the diagnosis, progression, and surgical follow-up of keratoconus. The classification proposed herein may present a novel benchmark in clinical work and future studies.

Keywords: diagnosis and classification, Pentacam topometric indices, Amsler-Krumeich keratoconus grading, surface variance, vertical asymmetry, keratoconus index, central keratoconus index, height asymmetry, height decentration, minimum radius of curvature

\section{Introduction}

Keratoconus is described as a degenerative bilateral, progressive, noninflammatory corneal disorder characterized by ectasia, thinning, and increased curvature. ${ }^{1,2}$ It is associated with loss of visual acuity particularly in relation to progressive cornea irregularity, 3,4 and usually is manifested asymmetrically between the two eyes of the same patient. ${ }^{5,6}$ Occasionally, the patient may present with symptoms of photophobia, glare, and monocular diplopia.

The problem of specificity and sensitivity of keratoconus assessment, particularly the diagnosis of early signs of ectasia and/or subclinical keratoconus, and for monitoring the progression of the disease, has been extensively studied. ${ }^{7}$ The commonly used 
options for the clinician include optically-based anterior segment imaging modalities, eg, Placido corneal topography ${ }^{8,9}$ and slit or Scheimpflug imaging, ${ }^{10}$ that provide corneal surface qualitative and quantitative data.

\section{Anterior segment topometric indices}

Rotating camera Scheimpflug imagery (Pentacam, Oculus Optikgeräte GmbH, Wetzlar, Germany), provides a multitude of corneal refractive (keratometric), topometric, tomographic, and pachymetric data. ${ }^{11,12}$ In addition, specific anterior-surface irregularity indices have been developed for the grading and classification of keratoconus development, as well as the post-operative assessment. ${ }^{13-19}$

The aim of this study was to investigate the values of these indices, the repeatability of their measurement, and their correlation with best spectacle-corrected distance visual acuity (CDVA), keratometry, and commonly used keratoconus classification in a large pool of clinically diagnosed keratoconic eyes.

\section{Patients and methods}

This study received approval from the Ethics Committee of the authors' institution, adherent to the tenets of the Declaration of Helsinki. Informed consent was obtained from each subject at the time of the first clinical visit. These cases were studied over the span of at least 2 years.

\section{Patient inclusion criteria}

The study group consisted of 212 cases that presented to the authors' institution. Subjects' ages ranged from 19-57 years (average $31.9 \pm 7.5$ years).

Each case was subjected to a complete ocular examination, including subjective refraction, CDVA measurement with this refraction, and slit-lamp biomicroscopy for clinical signs of keratoconus.

Inclusion criteria included a minimum age of 18 years and definite findings consistent with keratoconus, such as those described by the CLECK (Collaborative Longitudinal Evaluation of Keratoconus) group. ${ }^{20}$ Exclusion criteria included systemic disease, previous corneal surgery, history of chemical injury or delayed epithelial healing, and pregnancy or lactation during the study (for the female patients).

\section{Imaging, measurement, and analysis}

Anterior segment evaluation, including anterior segment imaging measurements with the Pentacam Scheimpflug rotating camera, was performed on each case. The device was calibrated according to manufacturer's recommendations prior to undertaking the measurements. The Pentacam measurements were obtained and processed via the examination software (version 1.17r47).

For each eye, four consecutive measurements were obtained and processed to test for data acquisition repeatability. The default settings, and 25 images per single acquisition were employed.

Linear regression analysis was performed to seek possible correlations. Descriptive and comparative statistics, analysis of variance between keratoconus Amsler-Krumeich stage subgroups, and linear regression were performed with statistics tools provided by Minitab ${ }^{\circledR}$ version 1.6 (Minitab Inc, Coventry, UK) and Origin version 9 (OriginLab Corporation, Northampton, MA, USA). $P$-values less than 0.05 in the paired analyses were considered statistically significant.

\section{Results}

\section{Keratometric and anterior surface topographic indices statistics}

The sample population consisted of 212 cases, which consisted of 65 female and 147 male patients. The preponderance towards males in the population is consistent with the authors' clinical experience in male/female incidence in keratoconic patients ${ }^{21}$ and keratoconus incidence studies. ${ }^{22}$ Of the 212 eyes, 113 were the right eye and 99 were the left eye. The average age of all patients was $31.77 \pm 7.23$ (range 19-57) years.

Table I Collective average, standard deviation, maximum, and minimum anterior keratometry and topometric indices, as measured in the $8 \mathrm{~mm}$ zone

\begin{tabular}{lllll}
\hline & Average & SD & Max & Min \\
\hline Anterior cornea & & & & \\
KI - flat (D) & 46.78 & \pm 5.89 & 78.50 & 33.70 \\
K2 - steep (D) & 51.05 & \pm 6.59 & 80.70 & 42.10 \\
Km - mean (D) & 48.80 & \pm 6.05 & 78.80 & 40.60 \\
Astigmatism (D) & -2.10 & \pm 6.05 & +11.30 & -12.40 \\
Anterior surface topometric indices & & & \\
ISV & 98.99 & \pm 47.43 & 262 & 14 \\
IVA (mm) & 1.05 & \pm 0.52 & 2.52 & 0.09 \\
KI & 1.28 & \pm 0.17 & 1.83 & 0.97 \\
CKI & 1.06 & \pm 0.07 & 1.30 & 0.90 \\
IHA ( $\mu$ m) & 30.60 & \pm 22.21 & 103.00 & 0.20 \\
IHD $(\mu \mathrm{m})$ & 0.091 & \pm 0.054 & 0.256 & 0.005 \\
Rmin (mm) & 6.07 & \pm 0.88 & 7.73 & 3.30 \\
CDVA & & & & \\
Decimal & 0.63 & \pm 0.25 & 1.00 & 0.10 \\
\hline Abreviations: CDVA & bst spctacl
\end{tabular}

Abbreviations: CDVA, best spectacle-corrected distance visual acuity; CKI, central keratoconus index; IHA, index of height asymmetry; IHD, index of height decentration; ISV, index of surface variance; IVA, index of vertical asymmetry; $\mathrm{KI}$, keratoconus index; Max, maximum; Min, minimum; Rmin, minimum radius of curvature; SD, standard deviation. 
Table 2 Intraindividual repeatability measurements for the seven anterior surface topometric indices, resulting as the standard deviation (\%) of the four consecutive acquisitions on each eye

\begin{tabular}{llllllll}
\hline & ISV & IVA & KI & CKI & IHA & IHD & Rmin \\
\hline Average & $2.77 \%$ & $4.63 \%$ & $2.15 \%$ & $2.02 \%$ & $43.78 \%$ & $4.67 \%$ & $1.50 \%$ \\
SD $( \pm)$ & $1.32 \%$ & $1.94 \%$ & $1.27 \%$ & $0.66 \%$ & $7.18 \%$ & $1.62 \%$ & $0.68 \%$
\end{tabular}

Abbreviations: $\mathrm{CKI}$, central keratoconus index; IHA, index of height asymmetry; IHD, index of height decentration; ISV, index of surface variance; IVA, index of vertical asymmetry; $\mathrm{KI}$, keratoconus index; Rmin, minimum radius of curvature; $\mathrm{SD}$, standard deviation.

The average \pm standard deviation CDVA (expressed decimally) for all eyes was $0.626 \pm 0.244$ (range $0.10-1.00$ ). Average, standard deviation, maximum and minimum corneal surface keratometry, and topometric indices for all eyes in the study are reported in Table 1. Intraindividual repeatability was assessed via the standard deviation of the four consecutive measurements undertaken for each eye. The average \pm standard deviation of repeatability for the seven topometric indices in all 212 eyes measured is reported in Table 2.

The sample was presented with an average keratometry on the anterior surface flat axis of $46.7 \pm 5.89 \mathrm{D}$ and $51.05 \pm 6.59$ D on the steep axis. The statistical analysis showed that $95 \%$ of the sample population had a steep axis keratometry $>$ 46.025 D, consistent with the CLEK group standards. ${ }^{20}$

\section{Topographic indices correlation with CDVA}

Paired statistics between CDVA and the index of height decentration (IHD), index of surface variance (ISV), index of vertical asymmetry (IVA), keratoconus index (KI), central keratoconus index (CKI), index of height asymmetry (IHA), and minimum radius of curvature ( $\mathrm{Rmin}$ ) (in the $8 \mathrm{~mm}$ zone) and specifically the coefficient of determination $\left(\mathrm{r}^{2}\right)$ and Pearson linear regression data between CDVA and the IHD, ISV, IVA, KI, CKI, IHA, and Rmin indices within all eyes in the study group $(n=212)$ are reported in Table 3.

The correlations between the seven keratoconic anterior surface topometric indices with CDVA are illustrated in Figure 1A-G. Specifically, the scatter and fitted line plots of ISV (Figure 1A), IVA (Figure 1B), KI (Figure 1C), CKI (Figure 1D), IHA (Figure 1E), IHD (Figure 1F), and Rmin (Figure $1 \mathrm{G}$ ) versus CDVA are plotted, in addition to the $95 \%$ confidence (CI) and 95\% prediction interval (PI) lines. The paired data present with coefficient of determination $\left(\mathrm{r}^{2}\right)$ of linear correlation with CDVA of 0.557 for ISV, 0.34 for IVA, 0.424 for KI, 0.396 for CKI, 0.107 for IHA, 0.393 for IHD, and 0.516 for Rmin. The Pearson correlation values versus CDVA were -0.746 for ISV, -0.584 for IVA, -0.680 for KI, -0.642 for CKI, -0.344 for IHA, -0.627 for IHD, and 0.718 for Rmin. In all cases, the $P$-value was $<0.0001$ (Table 3 ).

Table 3 Coefficient of determination $\left(r^{2}\right)$ and Pearson correlation data between best spectacle-corrected distance visual acuity and the seven anterior surface topometric indices within all eyes in the study group $(n=2 \mid 2)$

\begin{tabular}{|c|c|c|c|c|c|c|c|}
\hline & CDVA & IHD $(\mu \mathrm{m})$ & ISV & IVA $(\mathbf{m m})$ & KI & CKI & IHA $(\mu \mathrm{m})$ \\
\hline \multicolumn{8}{|l|}{ IHD } \\
\hline Pearson correlation & -0.627 & & & & & & \\
\hline$\left(r^{2}\right)$ & 0.393 & & & & & & \\
\hline \multicolumn{8}{|l|}{ ISV } \\
\hline Pearson correlation & -0.746 & 0.91 & & & & & \\
\hline$\left(r^{2}\right)$ & 0.55 & & & & & & \\
\hline \multicolumn{8}{|l|}{ IVA } \\
\hline Pearson correlation & -0.584 & 0.893 & 0.878 & & & & \\
\hline$\left(r^{2}\right)$ & 0.340 & & & & & & \\
\hline \multicolumn{8}{|l|}{ KI } \\
\hline Pearson correlation & -0.680 & 0.891 & 0.911 & 0.845 & & & \\
\hline$\left(r^{2}\right)$ & 0.424 & & & & & & \\
\hline \multicolumn{8}{|l|}{ CKI } \\
\hline Pearson correlation & -0.642 & 0.616 & 0.721 & 0.436 & 0.73 & & \\
\hline$\left(r^{2}\right)$ & 0.396 & & & & & & \\
\hline \multicolumn{8}{|l|}{ IHA } \\
\hline Pearson correlation & -0.344 & 0.524 & 0.484 & 0.422 & 0.467 & 0.252 & \\
\hline$\left(r^{2}\right)$ & 0.107 & & & & & & \\
\hline \multicolumn{8}{|l|}{ Rmin } \\
\hline Pearson correlation & 0.718 & -0.799 & -0.864 & -0.623 & -0.790 & -0.787 & -0.541 \\
\hline$\left(r^{2}\right)$ & 0.516 & & & & & & \\
\hline
\end{tabular}

Note: $P<0.001$ in all cases.

Abbreviations: CDVA, best spectacle-corrected distance visual acuity; CKI, central keratoconus index; IHA, index of height asymmetry; IHD, index of height decentration; ISV, index of surface variance; IVA, index of vertical asymmetry; KI, keratoconus index; Rmin, minimum radius of curvature. 

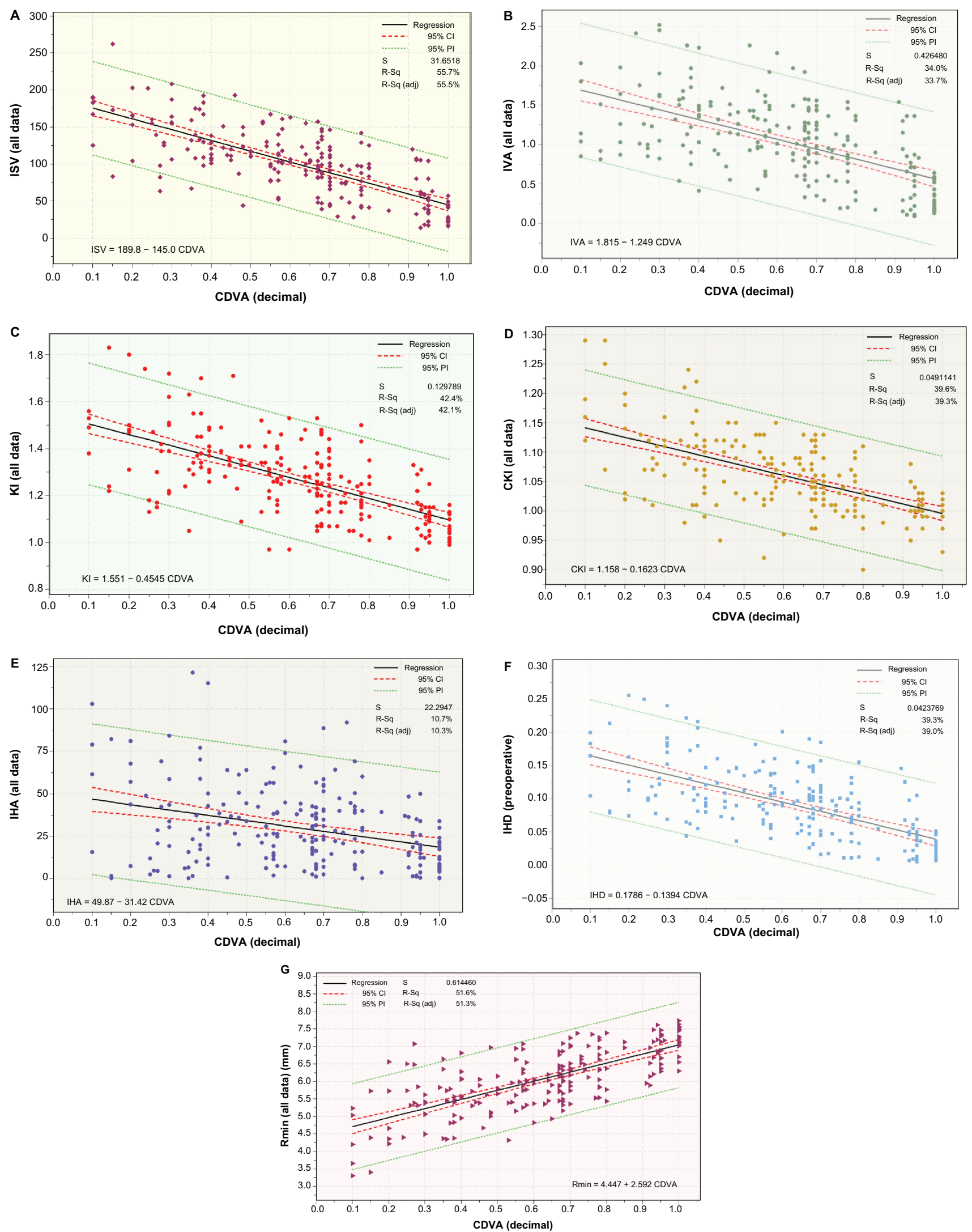

Figure I Scatter and fitted line plot of the seven anterior surface parameters versus CDVA with $95 \% \mathrm{Cl}$ and $95 \% \mathrm{PI}$. (A) ISV versus CDVA. (B) IVA versus CDVA. (C) KI versus CDVA. (D) CKI versus CDVA. (E) IHA versus CDVA. (F) IHD versus CDVA. (G) Rmin versus CDVA.

Abbreviations: CDVA, best spectacle-corrected distance visual acuity; $\mathrm{Cl}$, confidence interval; CKI, central keratoconus index; IHA, index of height asymmetry; IHD, index of height decentration; ISV, index of surface variance; IVA, index of vertical asymmetry; KI, keratoconus index; PI, prediction interval; Rmin, minimum radius of curvature. 


\section{Topographic indices correlation with keratoconus stages grading}

The 212 eyes were subjected to keratoconus AmslerKrumeich stages grading ${ }^{23}$ by the Pentacam software. The resulting grading designated $\mathrm{n} 1=$ ten eyes as Stage $\mathrm{I}$, $\mathrm{n} 12=$ eleven eyes as Stage I-II, $\mathrm{n} 2=32$ eyes as Stage II, n23 $=22$ eyes as Stage II-III, n3 = 54 eyes as Stage III, n34 = 45 eyes as Stage III-IV, and n 4 = four eyes as Stage IV.

The correlations between CDVA and the seven Scheimpflug anterior surface keratometric and topometric indices with the above keratoconus grading are illustrated in Figure 2A-H. Descriptive statistics for the keratoconus grading subgroups for CDVA and the seven topometric indices are presented in Table 4, and two-sample $t$-test results (not assuming equal variances) between the keratoconus grading subgroups for CDVA and the seven topometric indices are presented in Table 5.

\section{Discussion}

The Pentacam software compares the measured values with the means and standard deviations of a normal population, and helps provide color-coded "flags." For example, measured values which exceed the standard deviation by a factor of more than 2.5 are classified as abnormal and highlighted in yellow, and pathological values, ie, values that exceed the standard deviation by a factor of more than three, are highlighted in red. Namely, these indices are the following:

1. ISV: the unitless standard deviation of individual corneal sagittal radii from the mean curvature. ISV is thus an expression of the corneal surface irregularity. It is elevated in all types of corneal surface irregularity (eg, scars, astigmatism, deformities caused by contact lenses, pachymetry). According to the manufacturer's user manual, ${ }^{24}$ an ISV larger than 37 is considered abnormal (marked with yellow) and larger than 41 is pathological (marked with red).

2. IVA: measure (expressed in $\mathrm{mm}$ ) of the mean difference between superior and inferior corneal curvature (similar to the commonly used inferior/superior ratio). ${ }^{25}$ IVA is thus the value of curvature symmetry, with respect to the horizontal meridian as the axis of reflection. An IVA larger than 0.28 is considered abnormal, and larger than 0.32 is pathological.

3. KI: a unitless index is expressing the ratio between mean radius values in the upper and lower segment ( $\mathrm{r}$ sagittal superior to $r$ sagittal inferior). A KI value larger than 1.07 is considered abnormal and/or pathological.

4. CKI: the ratio between mean radius values in a peripheral ring divided by a central ring: $r$ sag (mean peripheral) to $r$ sag mean center (no units). CKI is elevated especially in central pachymetric, and increases with the severity of central keratoconus. A CKI value larger than 1.03 is considered abnormal and/or pathological.

5. IHA: the mean difference between height values superior minus height values inferior with horizontal meridian as mirror axis (expressed in $\mu \mathrm{m}$ )'. IHA is calculated by the height data symmetry comparison of the superior and inferior area, and provides the degree of symmetry of height data with respect to the horizontal meridian as the axis of reflection. IHA is similar to the IVA but based on corneal elevation, and is thus more sensitive. An IHA value larger than 19 is considered abnormal, and larger than 21 is pathological.

6. IHD: the value of the decentration of elevation data in the vertical direction (expressed in $\mu \mathrm{m}$ ), and is calculated from a Fourier analysis. This index provides the degree of decentration in the vertical direction, calculated on a ring with radius $3 \mathrm{~mm}$. An IHD value larger than 0.014 is considered abnormal, and larger than 0.016 is pathological.

7. Rmin: expressed in $\mathrm{mm}$. It is a measurement of the smallest radius of sagittal corneal curvature (ie, the maximum steepness of the cone). Values of Rmin less than $6.71 \mathrm{~mm}$ are considered abnormal and/or pathological, considering that the average radius of the anterior corneal surface is $7.87 \pm 0.27 \mathrm{~mm}^{26}$

Association with these indices with clinical keratoconus observations is provided by the manufacturer and is listed in Table 6.

The clinical suspicion of early-stage keratoconus may be based on refraction criteria such as a change in refractive power and the axis of astigmatism, fluctuating refraction, and several clinical findings (eg, conspicuous retinoscopy signs). Optical imaging, such as topometry and topography, provides valuable supplementary information, and it has long been supported that the contribution of proper evaluation and analysis of anterior surface irregularity derived from topography, ${ }^{27}$ or more recently from Pentacam topometry (eg, the seven topographic indices studied in this manuscript), may provide an invaluable aid in the diagnosis and progression evaluation of the disease. ${ }^{28}$ Only two reports have been identified that address this matter of correlation of the above Pentacam-derived indices with $\mathrm{CDVA}^{29}$ and the severity of keratoconus classification. ${ }^{30}$

The correlation between the seven anterior surface topographic indices and CDVA appears not very strong in our study. The Rmin $\left(\mathrm{r}^{2}=0.516, P<0.001\right)$ and ISV $\left(\mathrm{r}^{2}=0.557\right.$, $P<0.001)$ were found to be the strongest correlated indices with CDVA, in comparison to the other indices. The least 

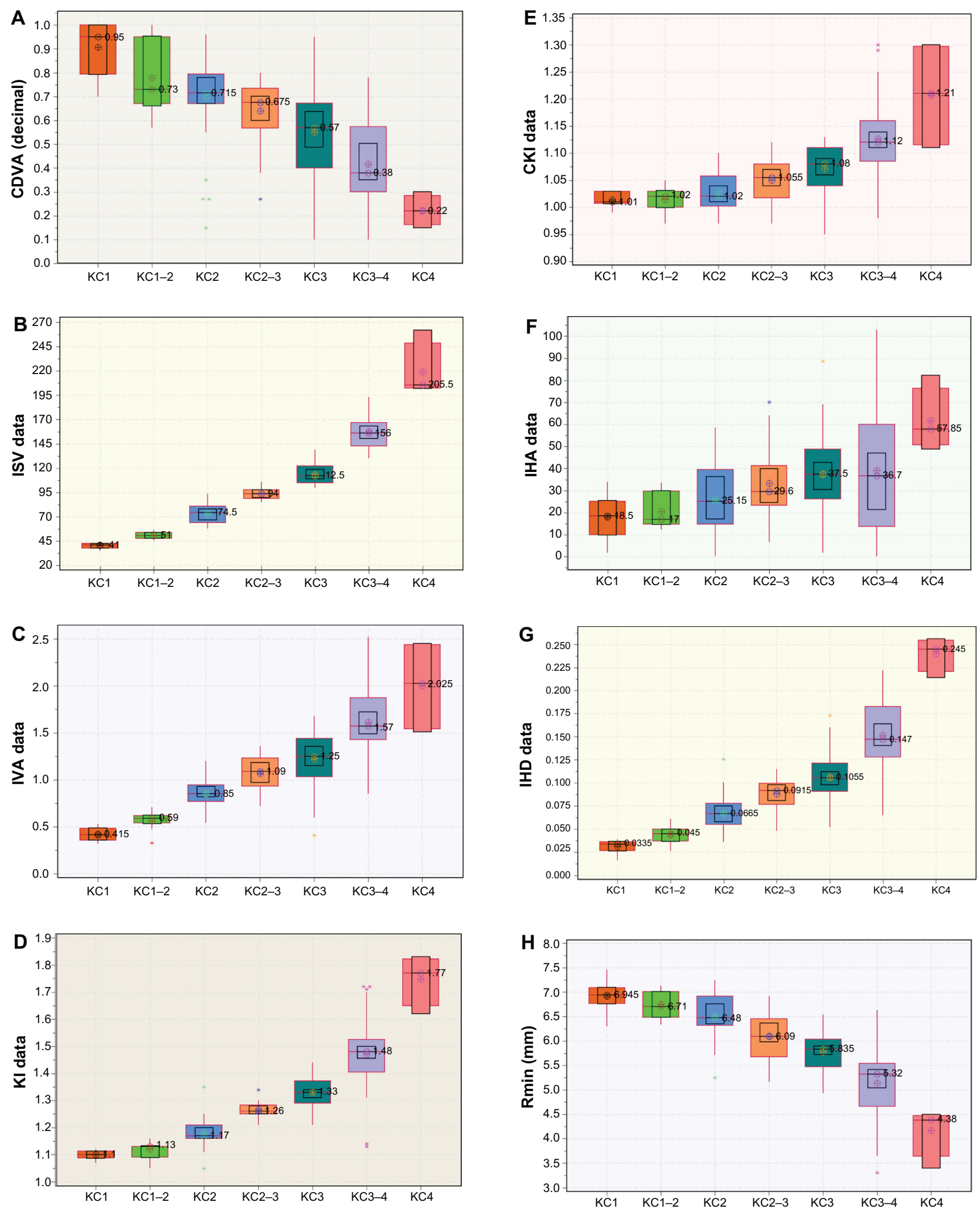

Figure 2 Box plots of measured parameters versus keratoconus grading, as produced by the Oculyzer ${ }^{\mathrm{TM}}$ software, showing median level (indicated by $\square$ ), average symbol ( $\square$ ), $95 \%$ median confidence range box (black line boxes), and interquartile intervals range box (red line boxes). (A) CDVA versus keratoconus grading. (B) ISV versus keratoconus grading. (C) IVA versus keratoconus grading. (D) KI versus keratoconus grading. (E) CKI versus keratoconus. (F) IHA versus keratoconus grading. (G) IHD versus keratoconus grading. $(\mathbf{H})$ Rmin versus keratoconus grading.

Abbreviations: CDVA, best spectacle-corrected distance visual acuity; CKI, central keratoconus index; IHA, index of height asymmetry; IHD, index of height decentration; ISV, index of surface variance; IVA, index of vertical asymmetry; KCI, keratoconus grading Stage I; KCl-2, keratoconus grading Stage I-II; KC2, keratoconus grading Stage II, KC2-3, keratoconus grading Stage II-III; KC3, keratoconus grading Stage III; KC3-4, keratoconus grading Stage III-IV; KC4, keratoconus grading Stage IV; KI, keratoconus index; Pl, prediction interval; Rmin, minimum radius of curvature. 
Table 4 Descriptive statistics for the keratoconus grading subgroups for age, best spectacle-corrected distance visual acuity, and the seven anterior surface topometric indices

\begin{tabular}{|c|c|c|c|c|c|c|c|}
\hline & \multicolumn{7}{|c|}{ Keratoconus grading } \\
\hline & Stage I & Stage I-II & Stage II & Stage II-III & Stage III & Stage III-IV & Stage IV \\
\hline \multicolumn{8}{|c|}{ Age (years) } \\
\hline Mean & 31.0 & 32.5 & 31.3 & 31.3 & 30.9 & 30.6 & 31.0 \\
\hline $\mathrm{SD}( \pm)$ & 8.4 & 7.6 & 7.8 & 6.0 & 6.7 & 7.3 & 8.4 \\
\hline \multicolumn{8}{|l|}{ CDVA } \\
\hline Mean & 0.907 & 0.779 & 0.695 & 0.64 & 0.55 & 0.416 & 0.2225 \\
\hline $\mathrm{SD}( \pm)$ & 0.107 & 0.166 & 0.202 & 0.133 & 0.188 & 0.187 & 0.0634 \\
\hline SEM & 0.034 & 0.05 & 0.036 & 0.028 & 0.026 & 0.028 & 0.032 \\
\hline \multicolumn{8}{|l|}{ ISV } \\
\hline Mean & 40.6 & 50.91 & 72.75 & 93.77 & 114.07 & 157.8 & 218.8 \\
\hline $\mathrm{SD}( \pm)$ & 2.88 & 3.56 & 9.32 & 5.25 & 9.51 & 17.9 & 29 \\
\hline SEM & 0.91 & I.I & 1.6 & I.I & 1.3 & 2.7 & 14 \\
\hline \multicolumn{8}{|l|}{ IVA } \\
\hline Mean & 0.422 & 0.5618 & 0.855 & 1.068 & 1.219 & 1.612 & 2.002 \\
\hline $\mathrm{SD}( \pm)$ & 0.0735 & 0.0994 & 0.134 & 0.194 & 0.258 & $0.36 \mathrm{I}$ & 0.497 \\
\hline SEM & 0.023 & 0.03 & 0.024 & $0.04 I$ & 0.035 & 0.054 & 0.25 \\
\hline \multicolumn{8}{|l|}{$\mathrm{KI}$} \\
\hline Mean & 1.10 & 1.12 & 1.1838 & 1.2664 & 1.3291 & 1.47 & 1.7475 \\
\hline $\mathrm{SD}( \pm)$ & 0.0163 & 0.0335 & 0.0522 & 0.027 & 0.0547 & 0.121 & 0.0929 \\
\hline SEM & 0.0052 & 0.01 & 0.0092 & 0.0058 & 0.0075 & 0.018 & 0.046 \\
\hline \multicolumn{8}{|l|}{ CKI } \\
\hline Mean & 1.014 & 1.0145 & 1.0291 & 1.05 & 1.07|| & 1.1269 & I.208 \\
\hline $\mathrm{SD}( \pm)$ & 0.0135 & 0.023 & 0.0352 & 0.0385 & 0.0394 & 0.0702 & 0.101 \\
\hline SEM & 0.0043 & 0.0069 & 0.0062 & 0.0082 & 0.0054 & 0.01 & 0.051 \\
\hline \multicolumn{8}{|l|}{ IHA } \\
\hline Mean & 18.05 & 20.55 & 26.5 & 33.3 & 37.7 & 39.3 & 61.7 \\
\hline $\mathrm{SD}( \pm)$ & 9.66 & 7.68 & 15.6 & 17.3 & 19.3 & 28.8 & 14.4 \\
\hline SEM & 3.1 & 2.3 & 2.7 & 3.7 & 2.6 & 4.3 & 7.2 \\
\hline \multicolumn{8}{|l|}{ IHD } \\
\hline Mean & 0.031 & 0.04355 & 0.0677 & 0.0878 & 0.1063 & 0.1512 & 0.24 \\
\hline $\mathrm{SD}( \pm)$ & 0.00723 & 0.00972 & 0.0183 & 0.0169 & 0.0266 & 0.0373 & 0.0185 \\
\hline SEM & 0.0023 & 0.0029 & 0.0032 & 0.0036 & 0.0036 & 0.0056 & 0.0093 \\
\hline \multicolumn{8}{|c|}{$\mathrm{Rmin}(\mathrm{mm})$} \\
\hline Mean & 6.922 & 6.755 & 6.52 & 6.104 & 5.775 & 5.146 & 4.165 \\
\hline $\mathrm{SD}( \pm)$ & 0.311 & 0.275 & 0.463 & 0.483 & 0.381 & 0.675 & 0.513 \\
\hline SEM & 0.098 & 0.083 & 0.082 & 0.1 & 0.052 & 0.1 & 0.26 \\
\hline
\end{tabular}

Abbreviations: CDVA, best spectacle-corrected distance visual acuity; CKI, central keratoconus index; IHA, index of height asymmetry; IHD, index of height decentration; ISV, index of surface variance; IVA, index of vertical asymmetry; KI, keratoconus index; Rmin, minimum radius of curvature; SD, standard deviation; SEM, standard error of the mean.

correlated index was IHA $\left(\mathrm{r}^{2}=0.107, P<0.001\right)$. This could be a result of significantly worse intraindividual repeatability of this index, possibly as a result of the complicated nature of its algorithm. As indicated in Table 2, repeatability, measured by the standard deviation of the measured index over four consecutive acquisitions, was as good as $1.50 \%$ on average for Rmin and up to $4.6 \%$ for IHD and IVA; however, the IHA index had a distinctive $43.78 \%$ average standard deviation among any four consecutive measurements, indicating very poor repeatability. In addition, the IHA index had the worst correlation with keratoconus severity (Figure $2 \mathrm{~F}$ ) with two stages not statistically significant and the remaining also borderline.
This study indicates that the correlation between keratoconus severity, and possibly very early progression indicators, and the anterior surface topographic indices can be better described with the ISV (with the exception of the highest stage [Stage IV], all other $P$-values were $<0.001$ ), followed by the IHD (with the exception of the lowest stage [Stage I], all other $P$-values were $<0.001$ ).

In addition, our results indicate that the visual performance in keratoconus was not clearly predicable for keratoconus severity, and thus CDVA cannot be a dependable indicator of keratoconus severity and/or progression and therefore cannot be employed in postoperative assessment aiming to arrest keratoconus progression by, for example, 
Table 5 Two-sample $t$-test results, not assuming equal variances, between successive pairs of keratoconus severity stages subgroups for best spectacle-corrected distance visual acuity and the seven anterior surface topometric indices

\begin{tabular}{|c|c|c|c|c|c|c|}
\hline & Stage I vs I-II & Stage I-II vs II & Stage II vs II-III & Stage II-III vs III & Stage III vs III-IV & Stage III-IV vs IV \\
\hline \multicolumn{7}{|l|}{$\overline{\text { CDVA }}$} \\
\hline Estimate for difference & -0.1279 & -0.0838 & -0.0558 & -0.0892 & -0.1344 & -0.1935 \\
\hline 95\% Cl for difference & $(-0.2552,-0.0006)$ & $(-0.2115,0.0440)$ & $(-0.1473,0.0357)$ & $(-0.1657,-0.0127)$ & $(-0.2095,-0.0593)$ & $(-0.2890,-0.0980)$ \\
\hline$t$-value & -2.12 & -1.36 & -1.22 & -2.34 & -3.55 & -4.58 \\
\hline$P$-value & 0.049 & 0.187 & 0.227 & 0.023 & 0.001 & 0.001 \\
\hline \multicolumn{7}{|l|}{ ISV } \\
\hline Estimate for difference & $|0.3|$ & 21.84 & 21.02 & 20.3 & 43.7 & 61 \\
\hline 95\% Cl for difference & $(7.35,13.27)$ & $(17.87,25.82)$ & $(17.02,25.03)$ & $(16.88,23.72)$ & $(37.79,49.62)$ & $(14.1,107.8)$ \\
\hline$t$-value & 7.33 & II.I & 10.55 & 11.86 & 14.76 & 4.14 \\
\hline$P$-value & $<0.001$ & $<0.001$ & $<0.001$ & $<0.001$ & $<0.001$ & 0.026 \\
\hline \multicolumn{7}{|l|}{ IVA } \\
\hline Estimate for difference & 0.1398 & 0.2929 & 0.2135 & 0.1503 & 0.3939 & 0.39 \\
\hline $95 \% \mathrm{Cl}$ for difference & $(0.0602,0.2195)$ & $(0.2139,0.3718)$ & $(0.1167,0.3103)$ & $(0.04 \mid 4,0.2592)$ & $(0.2660,0.5218)$ & $(-0.419,1.199)$ \\
\hline$t$-value & 3.69 & 7.67 & 4.48 & 2.77 & 6.13 & 1.53 \\
\hline$P$-value & 0.002 & $<0.001$ & $<0.001$ & 0.008 & $<0.001$ & 0.222 \\
\hline \multicolumn{7}{|l|}{ KI } \\
\hline Estimate for difference & 0.02 & 0.0638 & 0.0826 & 0.06271 & 0.1414 & $0.277 \mid$ \\
\hline $95 \% \mathrm{Cl}$ for difference & $(-0.0043,0.0443)$ & $(0.0357,0.0918)$ & $(0.0607,0.1045)$ & $(0.04394,0.08148)$ & $(0.1024,0.1804)$ & $(0.1186,0.4356)$ \\
\hline$t$-value & 1.76 & 4.66 & 7.59 & 6.66 & 7.26 & 5.56 \\
\hline$P$-value & 0.099 & $<0.001$ & $<0.001$ & $<0.001$ & $<0.001$ & 0.011 \\
\hline \multicolumn{7}{|l|}{ CKI } \\
\hline Estimate for difference & 0.00055 & 0.01452 & 0.0209 & 0.02111 & 0.0558 & 0.0806 \\
\hline $95 \% \mathrm{Cl}$ for difference & $(-0.01670,0.01779)$ & $(-0.00459,0.03362)$ & $(0.000 \mathrm{I}, 0.04 \mathrm{I})$ & $(0.00126,0.04096)$ & $(0.0323,0.0792)$ & $(-0.0842,0.2454)$ \\
\hline$t$-value & 0.07 & 1.56 & 2.03 & 2.15 & 4.75 & 1.56 \\
\hline$P$-value & 0.947 & 0.131 & 0.049 & 0.038 & $<0.001$ & 0.217 \\
\hline \multicolumn{7}{|l|}{ IHA } \\
\hline Estimate for difference & 2.5 & 5.93 & 6.82 & 4.38 & 1.58 & 22.44 \\
\hline 95\% Cl for difference & $(-5.58,10.59)$ & $(-1.37,13.22)$ & $(-2.45,16.10)$ & $(-4.74,13.50)$ & $(-8.45,11.60)$ & $(0.90,43.98)$ \\
\hline$t$-value & 0.65 & 1.65 & 1.48 & 0.97 & 0.31 & 2.68 \\
\hline$P$-value & 0.522 & 0.108 & 0.145 & 0.338 & 0.755 & 0.044 \\
\hline \multicolumn{7}{|l|}{ IHD } \\
\hline Estimate for difference & 0.01255 & $0.024 I I$ & 0.02012 & 0.01856 & 0.04487 & 0.0888 \\
\hline 95\% Cl for difference & $(0.00474,0.02035)$ & $(0.01522,0.03300)$ & $(0.01038,0.02985)$ & $(0.00836,0.02876)$ & $(0.03 \mid 65,0.05808)$ & $(0.0610,0.1166)$ \\
\hline$t$-value & 3.38 & 5.52 & 4.16 & 3.64 & 6.76 & 8.21 \\
\hline$P$-value & 0.003 & $<0.001$ & $<0.001$ & 0.001 & $<0.001$ & $<0.001$ \\
\hline \multicolumn{7}{|l|}{$\operatorname{Rmin}(\mathbf{m m})$} \\
\hline Estimate for difference & -0.167 & -0.235 & -0.416 & -0.329 & -0.629 & $-0.98 \mathrm{I}$ \\
\hline $95 \% \mathrm{Cl}$ for difference & $(-0.438,0.103)$ & $(-0.473,0.003)$ & $(-0.68 \mathrm{I},-0.15 \mathrm{I})$ & $(-0.563,-0.094)$ & $(-0.855,-0.403)$ & $(-1.858,-0.104)$ \\
\hline$t$-value & -1.30 & -2.02 & -3.16 & -2.85 & -5.56 & -3.56 \\
\hline$P$-value & 0.209 & 0.053 & 0.003 & 0.008 & $<0.001$ & 0.038 \\
\hline
\end{tabular}

Abbreviations: CDVA, best spectacle-corrected distance visual acuity; $\mathrm{Cl}$, confidence interval; $\mathrm{CKI}$, central keratoconus index; IHA, index of height asymmetry; IHD, index of height decentration; ISV, index of surface variance; IVA, index of vertical asymmetry; KI, keratoconus index; Rmin, minimum radius of curvature; vs, versus.

crosslinking with riboflavin. ${ }^{31}$ It is customary to assess severity based on visual function and, as noted above, appears to be deceiving. Clinicians must be cautious. For example, the data presented in this work (Figure 2A) suggest that CDVA is not very well correlated with the keratoconus severity, as the spread of CDVA measurements within the same "severity stage" (eg, Stage III, Stage III-IV) was found to be too large, and interfering with neighboring stages. The average coefficient of determination $\left(\mathrm{r}^{2}\right)$ was in the order of 0.5 , in agreement with previous studies. ${ }^{32}$
The above results are in agreement with the authors' past clinical experience with a significant number of keratoconic patients followed for over 15 years. The observation has been that visual acuity can present with large variations, and can sometimes be unexpectedly good for the corresponding keratometry and overall corneal asymmetry. This may be due to a "multifocal" and "soft," (ie, adaptable) cornea in addition to possible advanced neural processing development in the individual. However, these "advantages" are, to a large degree, compromised by the procedure of crosslinking 
Table 6 Classification stages of keratoconus adapted from the classical Amsler-Krumeich standards ${ }^{30}$

\begin{tabular}{|c|c|c|c|c|c|c|c|}
\hline & CDVA & ISV & KI & Other indices & Rmin, mm & Retinoscopy signs & Cornea slit-lamp observations \\
\hline $\begin{array}{l}\text { Pre-stage } \\
\text { (early signs) }\end{array}$ & $\begin{array}{l}20 / 20 \\
20 / 15\end{array}$ & $<30$ & $1.04-1.07$ & $\begin{array}{l}\text { All four indices } \\
\text { are "normal" }\end{array}$ & $7.8-6.7$ & $\begin{array}{l}\text { No clear light or } \\
\text { shadow movement. } \\
\text { Hint of "scissors" effect }\end{array}$ & $\begin{array}{l}\text { Clear cornea, unobtrusive. Horizontal, } \\
\text { oval, or round shades central or } \\
\text { slightly decentered, when observed } \\
\text { under direct ophthalmoscopy }\end{array}$ \\
\hline Level I & $\begin{array}{l}20 / 25- \\
20 / 15\end{array}$ & $30-55$ & $1.07-1.15$ & $\begin{array}{l}\text { Sometimes one } \\
\text { value within the } \\
\text { "abnormal" range }\end{array}$ & $7.5-6.5$ & $\begin{array}{l}\text { Distorted retinoscopic } \\
\text { reflex. Scissors effect }\end{array}$ & $\begin{array}{l}\text { Clear cornea. Fleischer's ring at the } \\
\text { apex base. Cone and cone base clearly } \\
\text { visible with direct ophthalmoscopy. } \\
\text { Decrease in apex thickness not visible, } \\
\text { but measurable }\end{array}$ \\
\hline Level 2 & $\begin{array}{l}20 / 60 \\
20 / 20\end{array}$ & $55-90$ & $1.10-1.25$ & $\begin{array}{l}\text { Often one value } \\
\text { within the } \\
\text { "abnormal" range }\end{array}$ & $6.9-5.3$ & $\begin{array}{l}\text { Clear scissors effect, } \\
\text { retinoscopy difficult } \\
\text { to perform }\end{array}$ & $\begin{array}{l}\text { Often cornea still clear, apex slightly } \\
\text { thinner and eventually decentered. } \\
\text { Partial or circular Fleischer's ring. } \\
\text { Vogt's striae may be visible }\end{array}$ \\
\hline Level 3 & $\begin{array}{l}20 / 125- \\
20 / 30\end{array}$ & $90-150$ & I.I5-I.45 & $\begin{array}{l}\text { At least one value } \\
\text { within the } \\
\text { "abnormal" range }\end{array}$ & $6.6-4.8$ & $\begin{array}{l}\text { Distinct scissors effect, } \\
\text { retinoscopy nearly } \\
\text { impossible to perform }\end{array}$ & $\begin{array}{l}\text { Apex thinner, decentered, and often } \\
\text { slightly cloudy. Clear and mostly } \\
\text { circular Fleischer's ring. Vogt's striae } \\
\text { clearly visible. Eventually Munson's } \\
\text { sign may appear }\end{array}$ \\
\hline Level 4 & $\begin{array}{l}<20 / 400 \\
20 / 100\end{array}$ & $>150$ & $>1.50$ & $\begin{array}{l}\text { At least one value } \\
\text { within the } \\
\text { "abnormal" range }\end{array}$ & $<5.00$ & $\begin{array}{l}\text { Retinoscopy impossible } \\
\text { to perform }\end{array}$ & $\begin{array}{l}\text { Cornea often scarred and opaque in } \\
\text { the apex. Munson's sign evident }\end{array}$ \\
\hline
\end{tabular}

Notes: Best spectacle-corrected distance visual acuity correction, with topography-based graduation indices (index of surface variance; keratometry index) compared with retinoscopy signs and clinical corneal slit-lamp observations.

Adapted from the WaveLight ${ }^{\circledR}$ Allegro Oculyzer ${ }^{\text {TM }}$ User Manual. ${ }^{24}$

Abbreviations: CDVA, best spectacle-corrected distance visual acuity; ISV, index of surface variance; KI, keratoconus index; Rmin, minimum radius of curvature.

with riboflavin applied in young (18-25 years old) keratoconus patients in long-term clinical observations.

Although not specifically studied herein, clinical assessment of this group is that CDVA is poorly correlated to keratoconus severity mainly in younger patients. As older keratoconus patients were encountered (ie, those over 30 years old and in most of those over 40 years old), their CDVA started to correlate with the ISV and IHD. This observation poses an even greater reason for clinicians to employ the strongest clinical suspicion in younger patients that may be at risk for developing keratoconus and may be labeled "normal" if a very good CDVA performance is maintained.

This may be explained by the higher elasticity of the pathologic cornea in younger keratoconus patients. This age-related difference may allow them to achieve high CDVA values with monocular testing by squinting and/or head tilting. ISV and IHD assessment in younger patients with relative low keratometric values may be the crucial factor in early diagnosis of keratoconus. We have encountered this clinical finding exaggerated in very young (18-22 years) keratoconic patients that had in the past undergone just cross-linking stabilization. We theorize that by increasing the biomechanical stability with CXL, these patients start to more appreciate the existing corneal irregularity. ${ }^{31,33,34}$

\section{Conclusion}

The ISV and IHA, both derived from Scheimpflug corneal imaging, may be more sensitive and specific tools than CDVA in evaluating early diagnosis and possible progression in keratoconus patients and corneal ectasia. They may become a novel benchmark for future studies, and may aid in the development of new keratoconus diagnostic and follow-up criteria.

\section{Disclosure}

Both AJK and GA occasionally consult for Alcon/Wavelight. The authors report no other conflicts of interest in this work.

\section{References}

1. Krachmer JH, Feder RS, Belin MW. Keratoconus and related noninflammatory corneal thinning disorders. Surv Ophthalmol. 1984;28(4):293-322.

2. Belin MW, Asota IM, Ambrosio R Jr, Khachikian SS. What's in a name: keratoconus, pellucid marginal degeneration, and related thinning disorders. Am J Ophthalmol. 2011;152(2):157-162.

3. Ambrosio R Jr, Caldas DL, da Silva RS, Pimentel LN, de Freitas VB. Impacto da análise do "wavefront" na refratometria de pacientes com ceratocone [Impact of the wavefront analysis in refraction of keratoconus patients]. Rev Bras Oftalmol. Rio de Janeiro: Sociedade Brasileira de Oftalmologia; 2010;69(5):294-300. Portuguese [with English abstract].

4. Kosaki R, Maeda N, Bessho K, et al. Magnitude and orientation of Zernike terms in patients with keratoconus. Invest Ophthalmol Vis Sci. 2007;48(7):3062-3068. 
5. Zadnik K, Steger-May K, Fink BA, et al; CLEK Study Group. Between-eye asymmetry in keratoconus. Cornea. 2002;21(7): 671-679.

6. Jones-Jordan LA, Walline JJ, Sinnott LT, Kymes SM, Zadnik K. Asymmetry in keratoconus and vision-related quality of life. Cornea. 2013;32(3):267-272.

7. Randleman JB, Trattler WB, Stulting RD. Validation of the Ectasia Risk Score System for preoperative laser in situ keratomileusis screening. Am J Ophthalmol. 2008;145(5):813-818.

8. Rabinowitz YS. Videokeratographic indices to aid in screening for keratoconus. J Refract Surg. 1995;11(5):371-379.

9. Abad JC, Rubinfeld RS, Del Valle M, Belin MW, Kurstin JM. Vertical D: a novel topographic pattern in some keratoconus suspects. Ophthalmology. 2007;114(5):1020-1026.

10. Ambrosio R Jr, Simonato RS, Luz A, Coca Velarde LG. Cornealthickness spatial profile and corneal-volume distribution: tomographic indices to detect keratoconus. J Cataract Refract Surg. 2006;32(11): 1851-1859.

11. McAlinden C, Khadka J, Pesudovs K. A comprehensive evaluation of the precision (repeatability and reproducibility) of the Oculus Pentacam HR. Invest Ophthalmol Vis Sci. 2011;52(10):7731-7737.

12. Swartz T, Marten L, Wang M. Measuring the cornea: the latest developments in corneal topography. Curr Opin Ophthalmol. 2007;18(4): $325-333$.

13. Li X, Yang H, Rabinowitz YS. Keratoconus: classification scheme based on videokeratography and clinical signs. J Cataract Refract Surg. 2009;35(9):1597-1603.

14. Greenstein SA, Fry KL, Hersh PS. Corneal topography indices after corneal collagen crosslinking for keratoconus and corneal ectasia: oneyear results. J Cataract Refract Surg. 2011;37(7):1282-1290.

15. Sonmez B, Doan MP, Hamilton DR. Identification of scanning slitbeam topographic parameters important in distinguishing normal from keratoconic corneal morphologic features. Am J Ophthalmol. 2007;143(3):401-408.

16. Markakis GA, Roberts CJ, Harris JW Jr, Lembach RG. Comparison of topographic technologies in anterior surface mapping of keratoconus using two display algorithms and six corneal popography devices. International Journal of Keratoconus Ectatic Diseases. 2012;1(3):153-157.

17. Faria-Correia F, Ramos IC, Lopes BT, et al. Topometric and tomographic indices for the diagnosis of keratoconus. International Journal of Keratoconus Ectatic Diseases. 2012;1(2):92-99.

18. Rufer F, Schroder A, Arvani MK, Erb C. Zentrale und periphere hornhautpachymetrie - normevaluation mit dem Pentacam-System [Central and peripheral corneal pachymetry - standard evaluation with the Pentacam system]. Klin Monbl Augenheilkd. Stuttgart: Thieme; 2005;222(2):117-122. German [with English abstract].

19. Emre S, Doganay S, Yologlu S. Evaluation of anterior segment parameters in keratoconic eyes measured with the Pentacam system. $J$ Cataract Refract Surg. 2007;33(10):1708-1712.
20. Zadnik K, Barr JT, Edrington TB, et al. Baseline findings in the Collaborative Longitudinal Evaluation of Keratoconus (CLEK) study. Invest Ophthalmol Vis Sci. 1998;39(13):2537-2546.

21. Kanellopoulos AJ, Asimellis G. Introduction of quantitative and qualitative cornea optical coherence tomography findings induced by collagen cross-linking for keratoconus: a novel effect measurement benchmark. Clin Ophthalmol. 2013;7:329-335.

22. Gordon-Shaag A, Millodot M, Shneor E. The epidemiology and etiology of keratoconus. International Journal of Keratoconus Ectatic Diseases. 2012;1(1):7-15

23. Krumeich JH, Daniel J, Knulle A. Live-epikeratophakia for keratoconus. J Cataract Refract Surg. 1998;24(4):456-463.

24. WaveLight GmbH. WaveLight ${ }^{\circledR}$ Allegro Oculyzer ${ }^{\mathrm{TM}} 1074$ User Manual (English). Erlangen: WaveLight GmbH; 2001.

25. Jafri B, Li X, Yang H, Rabinowitz YS. Higher order wavefront aberrations and topography in early and suspected keratoconus. $J$ Refract Surg. 2007;23(8):774-781.

26. Dubbelman M, Weeber HA, van der Heijde RG, Volker-Dieben HJ. Radius and asphericity of the posterior corneal surface determined by corrected Scheimpflug photography. Acta Ophthalmol Scand. 2002;80(4):379-383.

27. Maeda N, Klyce SD, Smolek MK, Thompson HW. Automated keratoconus screening with corneal topography analysis. Invest Ophthalmol Vis Sci. 1994;35(6):2749-2757.

28. Ho JD, Tsai CY, Tsai RJ, Kuo LL, Tsai IL, Liou SW. Validity of the keratometric index: evaluation by the Pentacam rotating Scheimpflug camera. J Cataract Refract Surg. 2008;34(1):137-145.

29. Lopes BT, Ramos IC, Faria-Correia F, et al. Correlation of topometric and tomographic indices with visual acuity in patients with keratoconus. International Journal of Keratoconus Ectatic Diseases. 2012;1(3): $167-172$.

30. Ishii R, Kamiya K, Igarashi A, Shimizu K, Utsumi Y, Kumanomido T. Correlation of corneal elevation with severity of keratoconus by means of anterior and posterior topographic analysis. Cornea. 2012;31(3): 253-258.

31. Kanellopoulos AJ. Comparison of sequential vs same-day simultaneous collagen cross-linking and topography-guided PRK for treatment of keratoconus. J Refract Surg. 2009;25(9):S812-S818.

32. Schoneveld P, Pesudovs K, Coster DJ. Predicting visual performance from optical quality metrics in keratoconus. Clin Exp Optom. 2009;92(3):289-296.

33. Kanellopoulos AJ, Binder PS. Collagen cross-linking (CCL) with sequential topography-guided PRK: a temporizing alternative for keratoconus to penetrating keratoplasty. Cornea. 2007;26:891-5.

34. Kanellopoulos AJ. Post-LASIK ectasia. Ophthalmology. 2007;114:1230.
Clinical Ophthalmology

\section{Publish your work in this journal}

Clinical Ophthalmology is an international, peer-reviewed journal covering all subspecialties within ophthalmology. Key topics include: Optometry; Visual science; Pharmacology and drug therapy in eye diseases; Basic Sciences; Primary and Secondary eye care; Patient Safety and Quality of Care Improvements. This journal is indexed on Submit your manuscript here: http://www.dovepress.com/clinical-ophthalmology-journal

\section{Dovepress}

PubMed Central and CAS, and is the official journal of The Society of Clinical Ophthalmology (SCO). The manuscript management system is completely online and includes a very quick and fair peer-review system, which is all easy to use. Visit http://www.dovepress.com/ testimonials.php to read real quotes from published authors. 